\title{
EFEKTIVITAS TERAPI CERMIN TERHADAP PERBAIKAN MOTORIK LENGAN PASIEN STROKE ISKEMIK AKUT
}

\author{
EFFECTIVENESS OF MIRROR THERAPY ON RECOVERY OF ARM MOTOR FUNCTION \\ IN PATIENTS WITH ACUTE ISCHEMIC STROKE
}

Machyono, * Andi Kurnia Bintang, * Jumraini Tammasse, * Cahyono Kaelan, *Abdul Muis, * Idham Jaya Ganda**

\section{ABSTRACT}

Introduction: Disability after stroke often happens and burden patients to perform their daily activity. Mirror therapy is an intervention focused on hand and leg movement of the affected side based of mirror neuron principal. This new technique using mirror is simple, affordable, and effective.

Aim: To investigate the effectiveness of mirror therapy (MT) on recovery of arm motor function in patients with acute ischemic stroke.

Methods: Randomized clinical trial with parallel design an patient with ischemic stroke admitted to Dr. Wahidin Sudirohusodo Hospital, Makassar, June to July 2017. Subjects were allocated into standard with mirror therapy group and standard therapy alone. Mirror therapy was done for 30 minutes everyday for 10 days. Action Research Arm Test (ARAT) at the first and the tenth day were compared using independent $t$ test.

Results: There were 32 subjects with 16 subjects in each group. Majority of subjects were men (59,4\%), age 45-54 years $(31,2 \%)$, had history of hypertension $(81,2 \%)$, came at the third day of onset $(28,1 \%)$, and a right side motor deficit $(59,4 \%)$. Difference in ARAT score was higher in group receiving standard + mirror therapy than in group receiving standard therapy alone $(15,56$ vs 7,69).

Discussion: Arm motor function recovery were significant on group receiving standard + mirror therapy compared to control after 10 days of intervention, especially grasping movement.

Keywords: Action research arm test, ischemic stroke, mirror therapy

\section{ABSTRAK}

Pendahuluan: Kelumpuhan ekstremitas pascastroke merupakan masalah yang sering terjadi dan sangat mengganggu pasien dalam melakukan aktivitas sehari-hari. Terapi cermin merupakan terapi intervensi yang difokuskan pada gerakan tangan atau kaki yang paresis akibat stroke dengan prinsip mirror neuron. Teknik ini relatif baru, sederhana, murah, dan efektif dengan menggunakan bantuan cermin.

Tujuan: Mengetahui efektivitas terapi cermin terhadap perbaikan motorik lengan pada pasien stroke iskemik akut.

Metode: Uji klinis terandomisasi dengan desain paralel terhadap pasien stroke iskemik akut yang dirawat di RSUP Dr. Wahidin Sudirohusodo, Makassar pada bulan Juni hingga Juli 2017. Subjek dibagi menjadi kelompok terapi yang mendapatkan tambahan terapi cermin dan kelompok kontrol yang hanya mendapatkan terapi standar. Terapi cermin dilakukan 30 menit setiap hari selama sepuluh hari. Dilakukan perbandingan skor action research arm test (ARAT) sebelum dan sesudah terapi dengan uji t tidak berpasangan.

Hasil: Didapatkan 32 subjek yang masing-masing terdiri dari 16 subjek pada tiap kelompok. Mayoritas subjek adalah laki-laki $(59,4 \%)$, usia $45-54$ tahun $(31,2 \%)$, memiliki riwayat hipertensi $(81,2 \%)$, onset terbanyak pada hari ke-3 $(28,1 \%)$, dan memiliki gangguan motorik pada sisi kanan $(59,4 \%)$. Rerata selisih skor ARAT lebih tinggi pada kelompok terapi standar dan terapi cermin dibandingkan kelompok terapi standar saja $(15,56$ vs 7,69).

Diskusi: Terdapat perbaikan fungsi motorik lengan yang signifikan antara kelompok dengan terapi cermin dan kelompok kontrol setelah 10 hari terapi cermin, terutama pada gerakan menggenggam (grasp).

Kata kunci: Action research arm test, stroke iskemik, terapi cermin

*Departemen Neurologi FK Universitas Hasanuddin, Makassar; **Departemen Ilmu Kesehatan Anak FK Universitas Hasanuddin, Makassar. Korespondensi: denise.dewanto@yahoo.com.

\section{PENDAHULUAN}

Stroke menduduki peringkat kedua penyebab kematian di seluruh dunia. Angka mortalitas pada tahun pertama serangan stroke pertama berkisar $20 \% .{ }^{1}$ Stroke juga menyebabkan disabilitas pada kehidupan seseorang, terutama pada stroke iskemik. Paralisis ekstremitas atas merupakan disabilitas yang paling menghambat pasien. ${ }^{2}$ Hilangnya fungsi lengan menyebabkan kesulitan untuk melakukan aktifitas sehari-hari, dan menyebabkan pasien menjadi 
tergantung orang lain. Target rehabilitasi stroke adalah mandiri secara fungsional sebagai individu dan peningkatan kualitas hidup pasien. Terapi konvensional masih belum cukup untuk memperbaiki fungsi motorik lengan. ${ }^{3}$

Terapi cermin merupakan terapi intervensi yang difokuskan pada gerakan tangan atau kaki yang paresis akibat stroke. Teknik ini relatif baru, sederhana, murah, dan terbukti mampu memperbaiki fungsi anggota gerak atas. Prosedur ini dilakukan dengan menempatkan cermin pada bidang midsagital pasien. Pasien kemudian melihat bayangan tangan yang sehat sehingga memberikan umpan balik visual yang dapat memperbaiki tangan yang lemah. ${ }^{4}$

Saat terapi cermin, eksitabilitas M1 (korteks motorik primer) dimodulasi oleh gerakan lengan ipsilateral dan observasi pasif dari gerakan lengan kontralateral, seperti yang tampak pada bayangan cermin. Dengan kata lain, pergerakan nyata dari lengan ipsilateral mengaktivasi M1 ipsilateral dan pengamatan gerakan pada cermin mengaktivasi M1 kontralateral. Perubahan simultan pada M1 diduga dapat memfasilitasi reorganisasi korteks yang sesuai untuk perbaikan fungsional. ${ }^{5}$

Hipotesis lainnya berkaitan dengan mirror neuron, yang diduga terdapat pada daerah frontotemporal dan girus temporal superior. Mirror neuron diketahui sebagai neuron bimodal yang teraktivasi ketika seseorang melakukan atau mengobservasi aktifitas motorik. Aktivasi bilateral dari korteks premotor pernah dilaporkan saat observasi objek yang berkaitan dengan aksi tangan atau lengan. ${ }^{4}$

Terapi cermin dapat membantu pemulihan fungsi motorik pada tangan yang lemah. Pasien menggerakan tangan yang sehat sambil melihat pantulannya di cermin (yang diposisikan di depan tangan yang sakit) sehingga menimbulkan ilusi seakan-akan tangan yang lemah dapat bergerak normal. ${ }^{6}$

\section{TUJUAN}

Untuk mengetahui efektivitas terapi cermin terhadap perbaikan motorik lengan pada pasien stroke iskemik akut.

\section{METODE}

Penelitian berupa uji klinis terandomisasi dengan desain paralel terhadap pasien stroke iskemik akut yang dirawat di RSUPDr. Wahidin Sudirohusodo, Makassar pada bulan Juni hingga Juli 2017. Subjek dibagi menjadi 2 kelompok, yaitu kelompok kontrol untuk subjek yang mendapatkan terapi standar stroke dan terapi rehabilitasi stroke, serta kelompok terapi yang mendapatkan terapi standar, terapi rehabilitasi stroke, dan terapi cermin. Kriteria inklusi meliputi stroke iskemik (dibuktikan dengan CT scan kepala) akut (onset 1-15 hari), kekuatan motorik $\geq 3$, berusia 35-70 tahun, dan menandatangani surat pernyataan persetujuan.

Adapun kriteria eksklusi adalah pasien dengan gangguan kesadaran, pendengaran, penglihatan, serangan ulangan pada sisi yang sama, stroke batang otak, stroke emboli, afasia, serta gangguan fungsi ginjal, hati, dan jantung yang dapat mengganggu perhatian atau konsentrasi. Subjek dikatakan drop out jika tidak mengikuti sesi latihan mirror therapy lebih dari 2 kali, meninggal dunia, atau mengundurkan diri karena alasan tertentu.

Terapi cermin dilakukan segera setelah kondisi pasien stabil dengan menggunakan cermin datar ukuran 20x25 inchi. Selama latihan pasien diharuskan untuk konsentrasi. Latihan terdiri dari 2 sesi dengan durasi 15 menit per sesi dan istirahat 5 menit antarsesi, diberikan sebanyak satu kali sehari selama 30 menit pada pagi hari hingga hari ke-10. Pasien diminta melihat bayangan tangan yang sehat pada cermin dan membayangkan seolah-olah tangan yang paresis dapat bergerak seperti tangan yang sehat. Pasien tidak diperbolehkan melihat tangan sisi yang sakit di balik cermin.

Selanjutnya pasien diinstruksikan untuk melakukan gerakan dasar secara simultan pada kedua anggota gerak atas. Gerakan tangan dapat berupa abduksi-adduksi, pronasi-supinasi, fleksi-ekstensi tangan, dan dapat diulang dengan kecepatan 1 detik/ gerakan. Jika pasien tidak bisa menggerakan tangan yang sakit, pasien akan diminta berkonsentrasi dan membayangkan seolah-olah pasien mampu menggerakan tangan yang sakit dengan melihat 
bayangan pada cermin. Saat melakukan terapi, pasien dalam posisi duduk di kursi menghadap ke meja dengan kedua tangan dan lengan diletakkan diatas meja. Cermin diletakkan pada bidang midsagital di depan pasien. Tangan sisi paresis diposisikan di belakang cermin, dan tangan sisi yang sehat diposisikan di depan cermin sehingga bayangan cermin tampak seolah-olah sebagai tangan yang paresis.

Action research arm test (ARAT) merupakan tes observasional yang digunakan untuk mengevaluasi fungsi motorik lengan. Tes ini dikembangkan oleh Lyle pada tahun 1981 sebagai modifikasi dari upper extremity function test untuk menilai proses pemulihan pada lengan akibat kerusakan pada tingkat kortikal. Waktu yang dibutuhkan untuk melakukan ARAT pada penderita stroke adalah sekitar 8-10 menit, tanpa diperlukan pelatihan khusus atau peralatan standar sebelumnya. Tes ini terdiri dari 4 gerakan (grasp, grip, pinch, dan gross movement) yang kemudian dibagi lagi menjadi 20 subbagian. Setiap subbagian akan mendapat nilai antara 0-3, sehingga rentang nilai skor ARAT adalah 0 sampai 57.

Penilaian dengan ARAT dilakukan oleh dokter yang sudah tersertifikasi terhadap semua subjek di kedua kelompok, yaitu pada hari pertama dan hari ke10. Selanjutnya dibandingkan selisih ARAT antara kedua waktu tersebut dan antara kedua kelompok.

Analisis data dilakukan dengan program SPSS versi 22. Digunakan uji Fisher dan Chi-square untuk menguji homogenitas variabel, serta uji t tidak

Tabel 1. Karakteristik Subjek pada Kedua Kelompok $(n=32)$

\begin{tabular}{|c|c|c|c|c|}
\hline Variabel & $\begin{array}{c}\text { Kelompok } \\
\text { Terapi Cermin } \\
\text { (n=16) }\end{array}$ & $\begin{array}{c}\text { Kelompok } \\
\text { Kontrol } \\
(\mathrm{n}=16)\end{array}$ & Total & $\mathbf{p}$ \\
\hline & n(\%) & n (\%) & n (\%) & \\
\hline \multicolumn{5}{|l|}{ Jenis Kelamin } \\
\hline - Laki-laki & $10(31,2)$ & $9(28,1)$ & $19(59,4)$ & $0,719^{*}$ \\
\hline - Perempuan & $6(18,8)$ & $7(21,9)$ & $13(40,6)$ & \\
\hline \multicolumn{5}{|l|}{ Kelompok Umur } \\
\hline - $<45$ tahun & $3(9,4)$ & $2(6,2)$ & $5(15,6)$ & $0,552 *$ \\
\hline - 45-54 tahun & $4(12,5)$ & $6(18,8)$ & $10(31,2)$ & \\
\hline - 55-64 tahun & $3(9,4)$ & $5(15,6)$ & $8(25)$ & \\
\hline - $\geq 65$ & $6(18,8)$ & $3(9,4)$ & $9(28,1)$ & \\
\hline \multicolumn{5}{|l|}{ Faktor Risiko } \\
\hline - $\mathrm{DM}$ & $1(3,1)$ & $1(3,1)$ & $2(6,2)$ & \\
\hline - Hipertensi & $14(43,8)$ & $12(37,5)$ & $26(81,2)$ & \\
\hline - Hipertensi \& DM & $1(3,1)$ & $3(9,4)$ & $4(12,5)$ & $0,792 * *$ \\
\hline \multicolumn{5}{|l|}{ Awitan (Hari) } \\
\hline - 2 & $3(9,4)$ & $2(6,2)$ & $5(15,6)$ & $0,891 * *$ \\
\hline - 3 & $4(12,5)$ & $5(15,6)$ & $9(28,1)$ & \\
\hline - 4 & $2(6,2)$ & $4(12,5)$ & $6(18,8)$ & \\
\hline - 5 & $4(12,5)$ & $2(6,2)$ & $6(18,8)$ & \\
\hline - 6 & $3(9,4)$ & $3(9,4)$ & $6(18,8)$ & \\
\hline \multicolumn{5}{|c|}{ Sisi Gangguan Motorik } \\
\hline - Sisi kanan & $10(31,2)$ & $9(28,1)$ & $19(59,4)$ & $0,719^{*}$ \\
\hline - Sisi kiri & $6(18,8)$ & $7(21,9)$ & $13(40,6)$ & \\
\hline \multicolumn{5}{|l|}{ Tingkat Pendidikan } \\
\hline - $<9$ tahun & 10 & $5(31,2)$ & $14(43,8)$ & $0,577 * *$ \\
\hline - $>9$ tahun & 6 & $11(68,8)$ & $18(56,2)$ & \\
\hline
\end{tabular}

*Uji Chi-square; ** Uji Fisher; DM: diabetes melitus. 
berpasangan untuk membandingkan kedua kelompok dengan batas kemaknaan $\alpha=5 \%$.

\section{HASIL}

Didapatkan 16 subjek (Tabel 1) pada kedua kelompok yang mayoritas adalah laki-laki $(59,4 \%)$ pada kelompok usia 45-54 tahun $(31,2 \%)$, dan memiliki riwayat hipertensi $(81,2 \%)$. Kejadian stroke paling banyak didapatkan pada onset harike-3 $(28,1 \%)$ dengan gangguan motorik di sisi kanan $(59,4 \%)$. Sebagian besar subjek menyelesaikan pendidikan $>9$ tahun $(56,2 \%)$. Tidak terdapat perbedaan rerata selisih skor ARAT pada hari pertama dan hari ke-10 yang bermakna antara laki-laki dan perempuan pada kedua kelompok, demikian pula antara sisi kerusakan motorik kanan dan kiri $(\mathrm{p}>0,05)$. Derajat kecacatan tiap subjek antara 2 kelompok kurang lebih sama, dilihat dari kekuatan motoriknya yang bernilai 3 sampai 4.

Pada hari ke-10 pemeriksaan ARAT (Tabel 2) terdapat perbedaan nilai yang signifikan antara kelompok dengan terapi cermin dan kelompok kontrol $(43,25 \pm 6,527$ vs $34,94 \pm 4,697, \mathrm{p}=0,000)$. Demikian pula terdapat perbedaan rerata selisih skor ARAT antara hari pertama dan hari ke-10, kelompok dengan terapi cermin memiliki selisih nilai ARAT yang bermakna dibandingkan kelompok kontrol $(15,56 \pm 4,381$ vs $7,69 \pm 1,662, p=0,000)$. Rerata selisih tersebut paling besar terdapat pada subbagian grasp
$(5,38 \pm 1,821$ vs $2,50 \pm 1,033)$ seperti pada Tabel 3 .

\section{PEMBAHASAN}

Rerata usia subjek pada penelitian ini adalah 56 tahun dengan kelompok usia terbanyak 45-54 tahun. Hal ini sedikit berbeda dengan penelitian Yavuzer yang rerata usia sampelnya 63 tahun. ${ }^{9}$ Namun hasil ini tidak jauh berbeda dengan penelitian Rambe dkk di Indonesia, khususnya Sumatra Utara, yang mendapatkan rerata usia 59 tahun. ${ }^{7}$

Mayoritas subjek adalah laki-laki, berbeda dengan Rambe dkk yang mendapatkan lebih banyak perempuan (52,7\%). ${ }^{7}$ Analisis statistik menunjukkan bahwa tidak ada perbedaan jenis kelamin yang signifikan antara 2 kelompok ( $\mathrm{p}>0,05)$.

Peningkatan rerata skor ARAT lebih besar pada kelompok terapi cermin. Hal ini sesuai dengan teori bahwa perbaikan motorik terbesar terjadi pada minggu pertama, sementara plateau terjadi setelah 6 bulan. Prognosis menjadi kurang baik apabila tidak terjadi perbaikan motorik dalam 1 bulan pertama. ${ }^{13}$ Kemungkinan terjadinya perbaikan yang dipengaruhi natural recovery pada kedua kelompok tidak dapat dihilangkan. Namun faktor-faktor perancu yang lain dapat diminimalkan dengan penerapan kriteria inklusi dan eksklusi.

Kelompok yang mendapatkan terapi standar saja mengalami perbaikan yang bermakna sesudah terapi. Hal ini mungkin disebabkan kombinasi terapi,

Tabel 2. Skor ARAT pada hari Pertama dan ke-10 (n=32)

\begin{tabular}{|c|c|c|c|c|}
\hline \multirow{2}{*}{ Variabel } & Kelompok Terapi Cermin & \multirow{2}{*}{ p } & Kelompok Kontrol & \multirow{2}{*}{$\mathbf{p}$} \\
\hline & Rerata+SD & & Rerata+SD & \\
\hline Hari ke-1 & $27,69 \pm 4,438$ & 0,000 & $27,25 \pm 4,374$ & 0,000 \\
\hline Hari ke-10 & $43,25 \pm 6,527$ & & $34,94 \pm 4,697$ & \\
\hline Selisih & $15,56 \pm 4,381$ & & $7,69 \pm 1,662$ & 0,000 \\
\hline
\end{tabular}

*Uji t tidak berpasangan; SD: standar deviasi; ARAT: action research arm test.

Tabel 3. Perbandingan Rerata Selisih Skor Sub-item ARAT antara Kedua Kelompok (n=32)

\begin{tabular}{lcccc}
\hline \multirow{2}{*}{ Variabel } & \multicolumn{2}{c}{ Kelompok Terapi Cermin } & \multicolumn{2}{c}{ Kelompok Kontrol } \\
\cline { 2 - 5 } & Rerata \pm SD & $\begin{array}{c}\text { Median } \\
\text { (Min-Maks) }\end{array}$ & Rerata \pm SD & Median \\
\hline Grasp & $5,38(1,821)$ & $5(2-8)$ & $2,50(1,033)$ & $2(1-4)$ \\
Grip & $3,31(1,352)$ & $3(1-6)$ & $1,89(0,957)$ & $2(1-3)$ \\
Pinch & $3,31(1,401)$ & $3(1-6)$ & $1,56(0,814)$ & $1(1-3)$ \\
Gross Movement & $3,56(1,632)$ & $3(1-6)$ & $1,75(1,065)$ & $2(1-3)$ \\
\hline
\end{tabular}

SD: standar deviasi; ARAT: action research arm test. 
perawatan yang baik, luas stroke, dan motivasi yang bagus. ${ }^{14}$ Derajat klinis umumnya membaik pada minggu pertama atau bahkan beberapa bulan setelah onset.

Terapi cermin terbukti lebih baik dibanding terapi rehabilitasi standar. Terapi ini juga bermanfaat pada stroke fase akut, subakut, dan kronis, serta dapat diintegrasikan pada terapi rehabilitasi stroke untuk meningkatkan fungsi motorik ekstremitas atas. ${ }^{13}$

Skor ARAT digunakan dalam penelitian ini dengan mempertimbangkan beberapa faktor, seperti waktu yang singkat (8-10 menit), cukup spesifik untuk menilai fungsi lengan, dan reliabilitas yang cukup tinggi. Namun terdapat kesulitan karena tidak didapatkan batas yang jelas antara nilai 1 dan 2 dalam penilaian ARAT, terutama pada pasien stroke akut. Modifikasi skor ARAT diperlukan untuk mengurangi unsur subjektivitas dalam interpretasi. ${ }^{15}$

Keterbatasan penelitian ini adalah variasi hari onset saat masuk penelitian dan waktu penelitian yang pendek. Dua hal ini dapat menjadi faktorfaktor perancu yang memengaruhi hasil penelitian ini. Pemeriksaan MRI fungsional (fMRI), dan kondisi emosi pasien dapat menjadi bahan evaluasi untuk penelitian selanjutnya. Demikian pula derajat kecacatan dan luas stroke sebaiknya dinilai dalam penelitian ini.

\section{KESIMPULAN}

Terdapat perbaikan fungsi motorik lengan yang signifikan antara kelompok dengan terapi cermin dan kelompok kontrol $(\mathrm{p}=0,000)$ setelah 10 hari terapi cermin, terutama pada subbagian grasp.

\section{DAFTAR PUSTAKA}

1. Endres M, Dimagl U, Moskowitz M. The ischemic cascade and mediator of ischemic injury. Dalam: Handbook of clinical neurology. 2009. h. 31-7.

2. Langhorne P, Coupar F, Pollock A. Motor recovery after stroke: a systematic review. Lancet Neurol. 2009;8(8):741-54.

3. Gurbuz N, Afsar SI, Ayas S, Cosar SNS. Effect of mirror therapy on upper extremity motor function in stroke patients: a randomized controlled trial. J Phys Ther Sci. 2016;28(9):2501-6.

4. Toh SFM, Fong KNK. Systematic review on the effectiveness of mirror therapy in training upper limb hemiparesis after stroke. Hong Kong J Occup Th. 2012;22(2):84-95.

5. Ezendam D, Bongers RM, Jannink MJA. Systematic review of the effectiveness of mirror therapy in upper extremity function. Disabil Rehabil. 2009;31(26):2135-49.

6. Sutbeyaz S, Yavuzer G, Sezer N, Koseoglu BF. Mirror therapy enhances lower-extremity motor recovery and motor functioning after stroke: a randomized controlled trial. Arch Phys Med Rehabil. 2007;88(5):555-9.

7. Rambe AS, Fithrie A, Nasution I, Tonam. Profil pasien stroke pada 25 rumah sakit di Sumatera Utara 2012 (survei berbasis rumah sakit). Neurona. 2013;30(2):63-68.

8. Hatem SM, Saussez G, della Faille M, Prist V, Zhang $\mathrm{X}$, Dispa D, dkk. Rehabilitation of motor function after stroke: a multiple systematic review focused on techniques to stimulate upper extremity recovery. Front Hum Neurosci. 2016;10:442.

9. Johansson BB. Current trends in stroke rehabilitation. A review with focus on brain plasticity. Acta Neurologica Scandinavica. 2011;123(3):147-59.

10. McDonnell M. Action research arm test. Aust J Physiother. 2008;54(3):220. 